\title{
Graphene-based papers as substrates for cell growth: Characterisation and impact on mammalian cells
}

DOI:

10.1016/j.flatc.2018.11.006

Document Version

Accepted author manuscript

Link to publication record in Manchester Research Explorer

Citation for published version (APA):

Jasim, D. A., Lozano, N., Bussy, C., Barbolina, I., Rodrigues, A. F., Novoselov, K. S., \& Kostarelos, K. (2018).

Graphene-based papers as substrates for cell growth: Characterisation and impact on mammalian cells.

FlatChem, 12, 17-25. https://doi.org/10.1016/j.flatc.2018.11.006

\section{Published in:}

FlatChem

\section{Citing this paper}

Please note that where the full-text provided on Manchester Research Explorer is the Author Accepted Manuscript or Proof version this may differ from the final Published version. If citing, it is advised that you check and use the publisher's definitive version.

\section{General rights}

Copyright and moral rights for the publications made accessible in the Research Explorer are retained by the authors and/or other copyright owners and it is a condition of accessing publications that users recognise and abide by the legal requirements associated with these rights.

\section{Takedown policy}

If you believe that this document breaches copyright please refer to the University of Manchester's Takedown Procedures [http://man.ac.uk/04Y6Bo] or contact uml.scholarlycommunications@manchester.ac.uk providing relevant details, so we can investigate your claim.

\section{OPEN ACCESS}




\section{Accepted Manuscript}

Graphene-Based Papers as Substrates for Cell Growth: Characterisation and Impact on Mammalian Cells

Dhifaf A. Jasim, Neus Lozano, Cyrill Bussy, Irina Barbolina, Artur Filipe Rodrigues, Kostya S. Novoselov, Kostas Kostarelos

PII: S2452-2627(18)30039-4

DOI: https://doi.org/10.1016/j.flatc.2018.11.006

Reference: FLATC 78

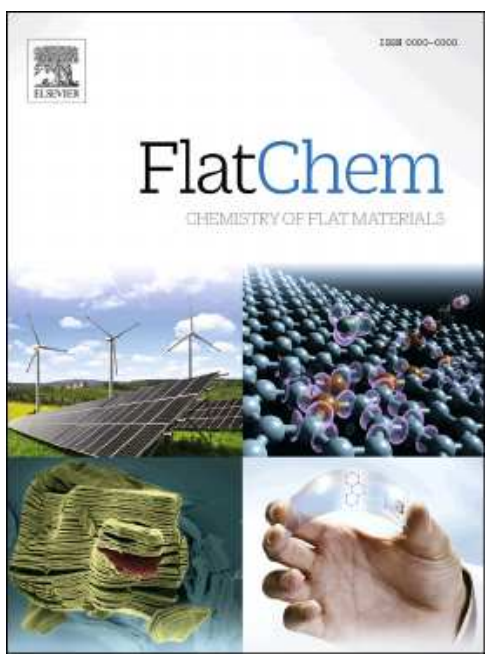

To appear in: $\quad$ FlatChem

Received Date: $\quad 16$ August 2018

Revised Date: $\quad 16$ November 2018

Accepted Date: $\quad 22$ November 2018

Please cite this article as: D.A. Jasim, N. Lozano, C. Bussy, I. Barbolina, A. Filipe Rodrigues, K.S. Novoselov, K. Kostarelos, Graphene-Based Papers as Substrates for Cell Growth: Characterisation and Impact on Mammalian Cells, FlatChem (2018), doi: https://doi.org/10.1016/j.flatc.2018.11.006

This is a PDF file of an unedited manuscript that has been accepted for publication. As a service to our customers we are providing this early version of the manuscript. The manuscript will undergo copyediting, typesetting, and review of the resulting proof before it is published in its final form. Please note that during the production process errors may be discovered which could affect the content, and all legal disclaimers that apply to the journal pertain. 


\section{Graphene-Based Papers as Substrates for Cell Growth: Characterisation and Impact on Mammalian Cells}

Dhifaf A. J asim ${ }^{a, b}$, Neus Lozano ${ }^{a, b}$, Cyrill Bussy ${ }^{a, b}$, Irina Barbolina ${ }^{b, c}$, Artur Filipe Rodrigues ${ }^{a, b}$, Kostya S. Novoselov, ${ }^{b, d}$ and Kostas Kostarelos ${ }^{a, b}, *$

${ }^{a}$ Nanomedicine Lab, Faculty Biology, Medicine and Health, AV Hill Building, The University of Manchester, Manchester M13 9PT, United Kingdom

${ }^{b}$ National Graphene Institute, The University of Manchester, Booth Street E, Manchester M13 9PL, United Kingdom

' Faculty of Life Sciences, University of Manchester, Manchester, UK

${ }^{d}$ School of Physics and Astronomy, University of Manchester, Oxford Road, Manchester, UK

* Correspondence should be addressed to: kostas.kostarelos@ manchester.ac.uk 


\section{Abstract}

Graphene based material (GBM) substrates are promising candidates for tissue engineering and as cell scaffolds owing to their outstanding properties that favour cell adhesion and growth. In this study, we report the fabrication and use of different oxidised graphene-based 'papers' as substrates for cell culture, using starting materials of different thickness and lateral dimensions. Graphite oxide (GTO) consisted of thicker sheets than the thinner large graphene oxide (I-GO) and small graphene oxide (s$\mathrm{GO}$ ) sheets. The 'papers' were prepared by vacuum filtration of the material suspensions and characterised by an array of experimental techniques. The substrates were then evaluated for cellular adhesion and proliferation with two epithelial cell lines that differ in their morphologies, the human lung cell culture (A549) model and the human neural cell culture (SH-SY5Y) model using microscopic analysis. Release of lactate dehydrogenase (LDH) in cell supernatants was measured to assess any cytotoxic responses. Our results revealed that the GO papers had similar physicochemical properties but differing topographies. The papers supported cell growth and no cytotoxicity was observed. These results suggest that substrates based on graphite and graphene oxide papers are suitable biocompatible cellular supports for anchorage-dependent cell growth and can be further explored for tissue engineering, regenerative medicine, substrates for cell growth and bionic applications.

Key Words: 2D, cell biology, substrates, membranes, films, nanomedicine 


\section{Introduction}

Graphene has attracted a great deal of interest recently due to its unique one atom thick 2-D honeycomb lattice that offers a variety of interesting physicochemical properties (1, 2). Graphene oxide (GO), graphene's oxidized analogue, presents various oxygen species on both sides of the planar structure that makes the material very hydrophilic. This has widened the use of graphene based materials (GBM) (3) for a large range of applications including biomedicine and tissue engineering (3-5).

GBM as potential cell substrates have been tested on various cell types (6-13) owing to the combination of their unique topographical, mechanical, electrical as well as their flexibility, biodegradability and mammalian cell biocompatibility. For instance, their unique simple topography facilitates the adhesion of anchorage-dependent cells (8). Their mechanical strength combined with high flexibility (14) and in vivo degradability (15) are essential requirements for an ideal restorable scaffold (16). GBM substrates have also been found to enhance the growth of neuronal cells due to the electrical conductivity of graphene that meet the requirements of the electroactive neuronal system $(9,12,14)$. In the context of tissue engineering, GO has been shown to offer properties that promote wound healing $(17,18)$. Regarding their safety profile, GBM and especially GO were shown to be biocompatible with various mammalian cells $(19,20)$, even though overall biocompatibility is still quite controversial (21) and highly depends on the forms of GBM used $(22,23)$. All these properties among others make oxidised GBM interesting candidates for use as cell substrates for designing novel scaffolding systems.

Amongst the different GBM substrates, two types varying by the thickness of the overall GBM layer can be found. For the thin ones, chemical vapour deposition (CVD) prepared graphene membranes $(8,9)$ and glass coverslips coated with GO based thin membranes (6) have been used by several groups and found to enhance cell growth. GO 3D hydrogel composites (24) and foams (14) were also tested as scaffolds to enhance and direct cellular growth in vivo. For the thick substrates, graphite oxide (GTO) papers (25), which are made of micrometer thick films of graphene oxide obtained by evaporation or filtration is also a potential candidate. GTO papers have exceptional stiffness and mechanical strength due to the intrinsic strength of the 2-D backbone and layered structure. It is also easy and relatively cheap to fabricate at industrial scale (26-28). These GTO based papers have been studied as flexible barriers and protective coating for a variety of applications including food packaging, anti-corrosion, anti-moulding, medical, chemical and electronics (29). Their nanometric porous nature provides unusual permeation properties resulting in proposals to use these materials in nano-filtration, separation and desalination (27-29). Other possible applications include nano-bionic devices (30), components of electrical batteries or super-capacitors, adhesive layers, electronic or optoelectronic components, and molecular storage (26).

In this study, three different starting materials were used to fabricate either GTO- or GObased papers using the thicker GTO sheets in comparison to two different-lateral dimension GO sheets; large (I-GO) and small (s-GO). They were prepared by vacuum filtration from material suspensions and characterised by several techniques including optical microscopy, SEM, Raman, FTIR, TGA and XPS. The papers were evaluated for cell growth (adhesion and proliferation) of A549 
lung cells and SH-SY5Y neuron-like cells using microscopy techniques. Using A549 lung cells as representative models, surface coverage of the paper by cells and cytotoxicity were also assessed. Our results revealed that despite differing in their topography, the different graphene-based papers had similar surface chemistry properties and this resulted in no cellular inhibition for the three papers. Moreover, cells cultured on oxidised GBM papers made of the larger starting materials had better viability, hence further demonstrating the biocompatibility and eventually benefit of using such graphene material-based substrates.

\section{Results}

Oxidised graphene based materials. I-GO was prepared from GTO, as described in the experimental section. The s-GO was prepared by the modified Hummers' method described in references (31-33), using chemical oxidation in strong acidic conditions. Structural characterisation of the GTO and the two GO materials by means of TEM and AFM analysis is shown in Figure 1. TEM images (Figure 1A) show the differences in the morphology and lateral dimension of the oxidised GBM. Figure 1B, 1C \& 1D, are the AFM height images that further show the morphology, lateral size and thickness of the two GOs (I-GO \& s-GO) approximately 1-2 nm in accordance with our previous studies (31-33) and above $10 \mathrm{~nm}$ for GTO. The AFM particle analysis in the latter figure demonstrates the lateral size and thickness distributions of both GO materials after counting several individual sheets, using the AFM height images. It was difficult to count the thickness and size distribution of the large and thick material GTO, as sheets were very large and covered whole grid areas, however the Flakes are at least microns in lateral dimension and very thick as seen in the TEM and AFM images Figure $\mathbf{A}$ and $\mathbf{1 B}$.

Preparation and structural characterisation of GBM papers. The papers were prepared by vacuum filtration of the material suspensions followed by air drying and careful peeling off the formed paper from the filter paper. Photographs in Figure 2A, show the macroscopic appearance of the GTO, I-GO and s-GO papers after peeling off; while Figure 2B shows microscopic topography of the papers under an optical microscope with upright optics at two different magnifications. Figure $\mathbf{2 C}$, shows the scanning electron microscopy (SEM) images, with the top panel (i) demonstrating the surface topography and the bottom panel (ii) showing the cross-section view, revealing the layered structure of the papers. The thickness of the paper prepared from GTO was more than 10 times thicker $(30 \mu \mathrm{m})$ than the two papers prepared from the graphene oxide materials (i.e. I-GO and s-GO), that was approximately $2 \mu \mathrm{m}$. schematics of the arrangement of the sheets in the paper is shown in the schematic in Figure 2D for GTO, I-GO and s-GO papers respectively.

Physicochemical characterisation of GBM papers. The physicochemical characterisation of the oxidised GBM papers is shown in Figure 3. The Raman spectra of the papers demonstrated the D and $G$ characteristic bands of graphene related materials (34). The intensity $I_{D} / I_{G}$ ratios of the papers 
were ranging from 1.43 to 1.50 . Comparison of the $I_{D} / l_{G}$ ratios of the papers to the starting materials (Figure S1) revealed a clear blue shift in the D peak (from $1330 \mathrm{~cm}^{-1}$ to $1320 \mathrm{~cm}^{-1}$ ) with no clear trend in the $G$ peak for all three papers (Figure S $1 \mathbf{A}$ ) and an increase in the $I_{D} / I_{G}$ ratio (Figure S 1B) only in the two papers prepared from the thin graphene oxide materials (I-GO and s-GO).

Fourier transform infrared (FT-IR) spectra are shown in Figure 3B; the functional groups of GO (hydroxyls, epoxides and carbonyls) have been identified. All three papers showed a broad band around $\left(3100-3600 \mathrm{~cm}^{-1}\right)$ due to the associated $\mathrm{O}-\mathrm{H}$ stretching vibrations, an intense peak at 1730 $\mathrm{cm}^{-1}$ for the $\mathrm{C}=\mathrm{O}$ stretching vibrations, and an intense peak at $1070 \mathrm{~cm}^{-1}$ for the C-O-C epoxy stretching vibration (35-41). The intensities related to aromatic and unsaturated bonds were shown by the bands intensities at $1535 \mathrm{~cm}^{-1}, 1640 \mathrm{~cm}^{-1}$ and a broad band around $3000-3100 \mathrm{~cm}^{-1}(38,40)$.

Figure 3C displays the TGA curves for the GTO, I-GO and s-GO papers. Two main weight loss steps were observed after subtracting around $10 \%$ of evaporated water from 25 to $100^{\circ} \mathrm{C}$. Percentages of weight losses are displayed on the same figures. The first step in weight loss observed between 100 and $260^{\circ} \mathrm{C}$ was due to the decomposition of the labile oxygen groups (such as carboxylic and aldehydes groups) and the removal of residual water. The second weight loss, due to the stable oxygen groups $(42,43)$, occurred between 260 and $700^{\circ} \mathrm{C}$. GTO had slightly lower thermal stability than the other samples, with a more pronounced first weight loss step. Nonetheless, the total weight loss percent (implying the degree of oxidation) was similar for all materials, as displayed on the figure inset $(41 \%, 42 \%$ and $39 \%$ for GTO, I-GO and s-GO respectively).

The XPS survey spectra and high resolution C1s XPS spectra for the papers are shown in Figure 3D, and Figure 3E. The spectra demonstrated successful oxidation process with the appearance of higher binding energy contributions ( $C-O, C=O, O-C=O$ and $\left.\pi-\pi^{*}\right)$ as previously reported $(44,45)$. In Table $\mathbf{S} 1$ the surface chemical composition of the papers from the survey spectra is shown. The purity of the papers, assuming only $C$ and $O$ content as $100 \%$ purity, was ranging between $98.9-99.1 \%$, with chemical impurities coming from $\mathrm{N}(<1 \%)$ and $\mathrm{S}(<0.7 \%)$. The $\mathrm{C}: \mathrm{O}$ ratio calculated for the papers were between $2.4-2.6$, indicating a similar oxygen content for all three papers studied. From the XPS C1s high resolution spectra (Figure 3E), GTO had a greater contribution of $\mathrm{C}-\mathrm{O}$ bonds compared to the other materials, resulting in a decreased abundance of carbon bonds. The remaining components did not change considerably (Table S2).

Cell growth of A549 and SH-SY5Y cells on GTO paper. We first tested the biocompatibility of one paper, namely GTO paper, with two different cell lines. Enhanced dark field microscopy was used to observe the A549 human lung cells and SH-SY5Y human neuron-like cells on the GTO papers and on the control substrates; results are provided in Figure S 2A. For both cell types, there was no significant difference in terms of adhesion, cell shape (usual morphology) and proliferation between culture on the GTO paper and on the control substrate. 4',6-diamidino-2-phenylindole (DAPI) staining of the A549 nuclei on the GTO papers compared to control substrate was then performed and observed using fluorescence microscopy, as shown in Figure S 2B. No significant difference between the two substrates was observed, confirming that cell proliferation was not disturbed by any substrate. Furthermore, A549 cells were cultured on GTO and I-GO papers then stained with the cytoskeletal 
marker $\alpha$-tubulin and DAPI and observed with a snapshot fluorescence microscope Figure S3 (A and B). Using ImageJ software the cell numbers were quantified in Figure $\mathbf{S} \mathbf{3 C}$ and cell morphology was assessed by measuring the cell aspect ratio in Figure S 3D. No statistical significance was detected in cells cultured on the GO substrates compared to cells cultured on the normal tissue culture substrates.

Cell growth and cytotoxicity of A549 cells on GBM papers. In a second stage, the A549 human lung cells, used as cell models, were grown on the different graphene oxide / graphite oxide papers and control substrates (either plastic or glass cover slips) as shown in Figure 4, Figure S4 and Figure S5. Upright optical microscopy was used to view the cells in these images. For the quantification of the cell coverage on the papers (Figure $\mathbf{4}$ and Figure S4B), ImageJ software was used, and the areas considered for that purpose are indicated in red and compared to cell uncovered substrates (Naïve and GO-papers) in Figure S5A. Approximately, 75\% of cell coverage was calculated for all substrates and no significant differences between papers and with control substrates (naïve) were observed. In addition, no difference in cell adhesion and morphology was observed, regardless of substrates used.

A lactate dehydrogenase (LDH) assay was performed to assess the cytotoxicity of the three papers to $A 549$ cells (Figure 4C). Significant differences in LDH release were detected in all groups when compared to lysed cells (LDH assay positive control). No significant cytotoxicity was detected for cells grown on paper or on control substrate. However, lower levels of LDH were significantly released from cells cultured on GTO and the thinner GO papers in comparison to cells grown on control substrate.

\section{Discussion}

The oxidised GBM papers were prepared from different starting materials exhibiting different structural characteristics including differing lateral dimensions and thickness distributions (Figure 1). This difference in the starting materials was selected to understand the impact on the arrangement of the sheets in the paper formation (Figure 2D). Different surface topographies and differences in the cross-section arrangement of the laminates within each paper were observed (Figure 2B and Figure 2C). The more homogeneous and structured distribution of the layers within the final paper was observed from the smaller and thinner material (s-GO) while more disorganized and randomly distributed layers was obtained for the largest starting materials, regardless of the thickness (GTO and I-GO). This is the first study to compare GO papers prepared from GBM with differing dimensions. Previous studies showed GO papers that were prepared from one starting GBM, forming interlocked layered structures with thicknesses ranging from $1 \mu \mathrm{m}$ (27) up to $25 \mu \mathrm{m}$ (26), made from crystals with typical sizes of few micrometres, separated by $1 \mathrm{~nm}$ distances (27).

The difference in dimensions was also affecting the interlayer distances and the sizes of capillaries (pores) created. For the same amount of starting materials (i.e. $15 \mathrm{mg}$ ) the thickness of the 
papers for the two thinner starting materials (I-GO and s-GO) was about $2 \mu \mathrm{m}$; while the thickness for the thicker starting material (GTO) increased drastically the thickness of the final paper, more than 10 folds, at about $27 \mu \mathrm{m}$. Therefore the permeation of water through the layers in the thicker paper will be different from the thinner papers (29), and will result in differences in the molecular transport through the interfacing cell membranes (27). Furthermore, the topographical features at the nanoscale could have a profound impact on the cell adhesion, proliferation, morphology and functionality $(6,8)$.

The physicochemical characterisation evidences a lot of similarities between the graphene oxide / graphite oxide papers (Figure 3). The metric of disorder (34) assessed via Raman $I_{D} / I_{G}$ ratio was the highest for the thicker material (GTO), while $I_{D} / I_{G}$ ratio for the thinner materials (I-GO and sGO) was reduced (Figure S1). Noticeably, after preparing the papers the $I_{D} / I_{G}$ ratio of the two thinner materials (I-GO and s-GO) increased, suggesting an increase of defects during formation of the papers. However, for GTO, the $\mathrm{I}_{\mathrm{D}} / \mathrm{I}_{\mathrm{G}}$ ratio did not change after preparing the paper. This implies that $\mathrm{I}_{\mathrm{D}} / \mathrm{I}_{\mathrm{G}}$ ratio is higher in the thicker stacked sheets, if in paper form or in solution. This could be related to the edge defects of the stacked carbon atoms. In addition, the FT-IR analysis showed that the amount and nature of functional groups were quite similar in the three papers studied. The TGA further revealed that a similar functionalization degree of $\sim 40 \%$ was obtained. And finally, the XPS clarified that a slightly lower C:O ratio was observed for the larger and thicker material (GTO) compared to the other two papers. The XPS C1s high resolution spectra (after deconvoluting the two peaks in 5 components) showed an increase in C-O bonds from GTO compared to the other materials (Table S2). On the other hand, the abundance of carbon-carbon bonds was decreased in this sample, whereas the remaining functionalities did not change considerably. This could be explained by the washing steps involved in the production of the two GO materials from GTO, which have been showed to remove acidic impurities.

Following the production of the different substrates, enhanced dark field microscopy (46) was used to visualize A549 and SH-SY5Y cells grown on GTO paper (Figure S 2A). These experiments using both A549 and SH-SY5Y were carried out on GTO paper only due to higher availability (fast and cheap synthesis) of this paper compared to the other two papers. Both cell types appeared adherent and their morphologies on the paper was comparable to cells cultured on the control substrate. In addition, fluorescence microscopy was used to detect DAPI molecular stain and evaluate cell proliferation on GTO. No apparent differences were detected between cells cultured on glass and cells cultured on GTO (Figure S 2B). Furthermore, no significant change in cell numbers and cell morphology was detected upon culturing the cells on GTO and I-GO substrates and staining them with the cytoskeletal marker $\alpha$-tubulin and nuclear stain DAPI compared to cells cultured on the normal tissue culture substrates (Figure S3). This is in agreement with previous studies (7, 8), where cell numbers, adherence and morphology using florescence microscopy were comparable to control substrates, when cultured on different carbon nanomaterial-coated substrates including graphene oxide.

Used as cell model, A549 lung cells were then cultured on the three different papers and examined using upright bright field optical microscopy to allow visualization of the cells on the dark 
opaque papers. Cell adhesion, size and morphology were comparable to the cells grown on the plastic or glass substrates. No significant differences in cell coverage between the three papers and the control without paper were detected, with approximately $75 \%$ coverage for all conditions. This agrees with previous studies. A previous report using fibroblast cells indicated similar to control cellular coverage on different carbon based material substrates (7), other reports indicated even enhanced growth on GBM substrates especially of neuronal cells $(9,10,13)$.

On the other hand, LDH cytotoxicity assay (Figure $\mathbf{4 C}$ ) demonstrated that A549 cells cultured on papers made of the large starting materials (GTO and I-GO) had significantly lower LDH release compared to cells grown on control substrate. This suggests that cells grown on papers with specific topographies (which may be associated with a higher roughness) were healthier and survived longer on those papers compared to control substrates. Other studies have also demonstrated biocompatibility and possibly enhancement of cellular growth on GO substrates $(6,11,12)$. However, further investigations including AFM analysis of the roughness of the papers and of the biomechanical behaviours of the cells on each paper are required.

\section{CONCLUSION}

In this work, we have studied the ability of three different GBM papers to interface with human cells. Despite showing different topographical but similar structural and physicochemical characteristics, the three papers had no impact on the cell adhesion, proliferation and morphology. However, cells cultured on tissue culture plastic released more LDH enzyme compared to cells cultured on the GBM papers, suggesting that GBM papers support cell viability. Our findings highlight the great potential for using GBM papers as potential tissue scaffolds, substrates for cell growth or even for nano-bionic devices. 


\section{Experimental}

Preparation of GO from GTO. GTO was a kind gift from BGT Materials Limited (previously BlueStone Global Tech, UK). I-GO was prepared from GTO by 3-4 times washing with Milli Q water and sedimentation by centrifugation as described in Barbolina, I et al. (21). This is followed by sonication of the solution for 0.5-1 h. Then the I-GO is separated by a two-step centrifugation process for $20 \mathrm{~min}$ at 8,000 rpm each. Additional washing of the as prepared GO in Milli Q water by centrifugation for $30 \mathrm{~min}$ at 17,000 rpm is followed.

Synthesis of s-GO. s-GO was prepared from Chinese flake graphite (Branwell), by the modified Hummers method described in (31-33). Briefly, $0.4 \mathrm{~g}$ of graphite was mixed with $0.2 \mathrm{~g}$ of sodium nitrate $\left(\mathrm{NaNO}_{3}\right)$ in a beaker, and then $9.2 \mathrm{~mL}$ of $99 \%$ sulphuric acid $\left(\mathrm{H}_{2} \mathrm{SO}_{4}\right)$ was added slowly to the mixture, which was continuously stirred with a magnetic stirrer. The temperature was monitored not to exceed $20^{\circ} \mathrm{C}$ by using an ice bath. After obtaining a homogenized mixture, $1.2 \mathrm{~g}$ of potassium permanganate $\left(\mathrm{KMnO}_{4}\right)$ was added slowly. The temperature was monitored again and did not exceed $20^{\circ} \mathrm{C}$. Then the mixture was removed from the ice bath and the temperature started to rise gradually. This was maintained for 30 min until the mixture started thickening and became a paste of dark brown/green colour. Deionized $\mathrm{H}_{2} \mathrm{O}$ was added slowly while stirring at the same time. Violent effervescence and rapid increase of temperature was observed. Temperature was monitored carefully and was kept between $98-100^{\circ} \mathrm{C}$ for another $30 \mathrm{~min}$ with the aid of a hot plate. The mixture was further diluted with $56 \mathrm{~mL}$ of Milli Q water and $6 \mathrm{~mL}$ hydrogen peroxide $30 \%\left(\mathrm{H}_{2} \mathrm{O}_{2}\right)$ was added gradually for the reduction of the residual $\mathrm{KMnO}$, manganese dioxide $\left(\mathrm{MnO}_{2}\right)$ and manganese heptoxide $\left(\mathrm{Mn}_{2} \mathrm{O}_{7}\right)$ to soluble manganese sulphate $\left(\mathrm{MnSO}_{4}\right)$ salts. The resulting suspension was centrifuged at $9000 \mathrm{rpm}$ for $20 \mathrm{~min}$ and the supernatant was discarded, this was repeated until the supernatant had a pH of about 6 and the GO gel-like layer appeared on top of the oxidation by products. This layer was then extracted carefully using warm Milli Q water in order to avoid remixing of this layer with graphite oxide sediments.

Preparation of GBM papers. GBM papers were prepared from the GBM solutions using $15 \mathrm{~mL}$ of $1 \mathrm{mg} / \mathrm{mL}$ prepared by vacuum filtration using Whatman Anodisc 47 (0.2 $\mathrm{mm}$, d-47 mm; Catalogue number 6809-5077) filter papers. The papers were further left to dry in air at room temperature and peeled of the filter paper gently. For cell culture experiments, the papers were cut into suitable sizes, enough to cover the well plates and sterilized by UV light for $30 \mathrm{~min}$ on each side. Tissue culture (TC) plastic was used as control for assessing cell behaviours.

Transmission electron microscopy (TEM). Twenty $\mu \mathrm{L}$ of GBM suspension was placed on a formvar / carbon coated copper grid that was glow discharged for $30 \mathrm{sec}$. Millipore filter paper was used to remove the excess of material. TEM was then performed using a T-12 Biotwin transmission electron microscope (Techni, Netherlands) equipped with an Orius CCD SC100 camera (GATAN, UK) at $100 \mathrm{KeV}$.

Atomic force microscopy (AFM). A Bruker Multimode 8 was used in tapping-mode with an J-type scanner, Nanoscope VI controller, Nanoscope v614r1 control software (Veeco, Cambridge, UK) and a silicon tapping tip (NSG01, NTI-Europe, Apeldoorn, The Netherlands) of $10 \mathrm{~nm}$ curvature radius, mounted on a tapping mode silicon cantilever with a typical resonance frequency $283-374 \mathrm{kHz}$ and a force constant of $12-103 \mathrm{~N} / \mathrm{m}$ (Bruker OTESPA, UK). Images were taken in air, by depositing $40 \mu \mathrm{L}$ of the sample on a freshly cleaved mica surface (Agar Scientific, Essex, UK) coated with poly-L-Lysine 0.01\% (Sigma-Aldrich, UK) and allowed to adsorb for 2 min. Excess unbound material was removed by washing with Milli $Q$ water, and then allowed to dry in air; this step was repeated once. Size and thickness distributions were carried out using Nanoscope Analysis software 
v1.40 which automatically counted the lateral dimension and height of about 100 to 300 graphene sheets after setting a threshold.

Scanning Electron Microscopy (SEM). SEM imaging was performed using an FEI Quanta 250 ESEM operating in high vacuum. Dried GBM paper samples were mounted using carbon tabs onto a thin metal sheet and then placed vertically in a suitable holder to obtain a cross-section image and then horizontally to observe the surface.

Raman Spectroscopy. Raman Spectra of starting materials were recorded after preparing the aqueous dispersions and drop casting them on glass slides and evaporating the solvent, while papers were attached to the glass slide by adhesive tape. Measurements were carried out using a 50x objective at $780 \mathrm{~nm}$ LASER excitation using a DXR Raman microscope (Thermo Scientific, UK). Three spectra corresponding to 3 spots per material (dried suspensions or papers) were recorded and then averaged to give a final value per material.

Fourier Transform Infrared Spectroscopy (FT-IR). Spectroscopy at the mid-infrared range was carried out on the dry papers using a PerkinEImer Spectrum 100 spectrophotometer and the transmittance results were analysed with the built-in spectrum software.

Thermal Gravimetric Analysis (TGA). Thermogravimetric analysis (TGA) of papers using a Pyris 6, PerkinElmer Ltd. was used from 25 to $800^{\circ} \mathrm{C}$ at $10^{\circ} \mathrm{C} / \mathrm{min}$. GBM paper samples (1-2 mg) were weighed into a ceramic crucible. Nitrogen $(20 \mathrm{~mL} / \mathrm{min})$ was used as a purge gas.

X-Ray Photoelectron Spectroscopy (XPS). The surface chemical composition of GBM papers was studied by X-ray Photoelectron Spectroscopy (XPS) at NEXUS facility (the UK's National EPSRC XPS Users' Service, hosted by nanoLAB in Newcastle-upon-Tyne). XPS was recorded using a Thermo Theta Probe XPS spectrometer with a monochromatic Al K-a source of $1486.68 \mathrm{eV}$. The survey XPS spectra were acquired with pass energy (PE) of $200 \mathrm{eV}, 1 \mathrm{eV}$ step size, $50 \mathrm{~ms}$ dwell time and averaged over 5 scans. The etching was 90 $\mathrm{sec}$. The high resolution C1s XPS spectra were acquired with PE of $40 \mathrm{eV}, 0.1 \mathrm{eV}$ step size, $100 \mathrm{~ms}$ dwell time and averaged over 20 scans. Spectral analysis was performed using CasaXPS software (Casa Software Ltd, UK). Spectra from insulating samples were charge corrected by shifting all peaks to the adventitious carbon $\mathrm{C}$ is spectral component binding energy set to $284.6 \mathrm{eV}$. After a Shirley background subtraction, high-resolution C1s spectra were deconvoluted in 5 components, with binding energy values constrained according to NIST's XPS and la surface databases:

$$
\begin{aligned}
& \pi-\Pi^{*}: 290.0-292.0 \mathrm{eV} \\
& \text { O-C=O: } 288.6-290.0 \mathrm{eV} \\
& \text { C=O: } 286.8-287.8 \mathrm{eV} ; \\
& \text { C-O: } 285.5-286.6 \mathrm{eV} \\
& \text { C-C and C=C: } 284.5-284.6 \mathrm{eV} .
\end{aligned}
$$

Apart from the $\pi-\Pi^{*}$ peak, all components had their full width half maximum values fixed to the same value, constrained between 0.5 and $2 \mathrm{eV}$. All functional groups were fitted to a Gaussian-Lorentzian (70:30) function, whereas the graphitic peak, corresponding to $\mathrm{C}-\mathrm{C}$ and $\mathrm{C}=\mathrm{C}$ bonds, was fitted using an asymmetric Lorentzian function.

Cell Cultures. Human A549 epithelial lung carcinoma cells (ATCC, CCL-185) were maintained and passaged in F12 Ham media supplemented with 10\% FBS (Fetal bovine serum, ThermoScientific-Life Technologies, UK), 1\% 
of penicillin/streptomycin (ThermoScientific-Life Technologies, UK), at $37{ }^{\circ} \mathrm{C}$ in $5 \% \mathrm{CO}_{2}$. Human SH-SY $5 Y$ epithelial neuroblastoma cells (ATCC, CRL-2266) were grown in DMEM complemented with 10\% FBS 1\% nonessential amino acids (ThermoScientific-Life Technologies, UK), and $1 \%$ of penicillin/streptomycin in at $37{ }^{\circ} \mathrm{C}$ in $5 \% \mathrm{CO}_{2}$. Both cells were passaged twice a week using trypsin-EDTA $0.05 \%$ (ThermoScientific-Life Technologies, UK), when reaching $80 \%$ confluence. Cells were seeded into 96-well plates (10,000 cells/well), 24 well plates $(50,000$ cells/well) or 12 -well plates (100,000 cells per well) depending on the assay and left to adhere overnight at $37{ }^{\circ} \mathrm{C}$ in the $\mathrm{CO}_{2}$ incubator; cells were either seeded on the sterilized GBM papers or on sterile tissue culture (TC) plastic used as control.

Cell coverage visualization and microscopy. Prior to cell imaging, cells were fixed with ice-cold methanol for $10 \mathrm{~min}$ and then leave to dry for an extra $10 \mathrm{~min}$. Enhanced dark field (dark field reflected light) microscopy using a AxioLab A1 scope (Zeiss, UK) was used to visualise A549 and SH-SY5Y cells cultured on the GBM papers. Enhanced contrast images were created by the Zen software (Zeiss, UK) for both cell types. A549 cells were cultured for $24 \mathrm{~h}$ and stained with DAPI molecular stain (Molecular probes, D1306) and visualized using an upright stereo-fluorescent microscope (LEICA DFC 365FX). Cell monolayers and plane GBM paper surfaces were visualized and photographed using upright optical microscopy. Experiments were performed two replicates and cell coverage was determined using ImageJ software taking the average of three different fields at 10x.

Cell counts and morphology. Prior to cell imaging, the cultured cells were washed with PBS and fixed with $4 \%$ paraformaldehyde for $15 \mathrm{~min}$ at room temperature. This was followed by ice-cold methanol permeabilization for 5 min at $-20^{\circ} \mathrm{C}$, followed by washing with PBS three times. The cells were then blocked for $1 \mathrm{~h}$ with $5 \%$ normal goat serum and $0.3 \%$ Triton in PBS. They were then incubated overnight at $4{ }^{\circ} \mathrm{C}$ with either $\alpha$-tubulin

(Sigma, no. T9026). The next day, they were washed with PBS three times and incubated with the fluorochromeconjugated secondary antibodies (antimouse-Cy3) for 1 h at room temperature and then washed three times with PBS. The coverslips were then mounted with Prolong Gold Anti-Fade Reagent with DAPI (Cell signalling, no. 8961) and left to dry at room temperature. Images were then captured using Zeiss Axioimager.D2 upright microscope using a [10x and 40x] objective and captured using a Coolsnap HQ2 camera (Photometrics) through Micromanager software v1.4.23. Specific band pass filter sets for [DAPI and Cy3] were used to prevent bleed through from one channel to the next. $\alpha$-tubulin was excited in the Cy3 channel ( $550 \mathrm{~nm}$ excitation and $570 \mathrm{~nm}$ emission). DAPI channel was used for the nuclear counter stain ( $350 \mathrm{~nm}$ excitation and $470 \mathrm{~nm}$ emission). All images were analysed using, Fiji/ ImageJ software. Experiments were performed two replicates and cell number was determined taking the average of several different fields at 10x. The cell shape change depended on determining the aspect ratio of cells from dividing the maximum diameter of the cell by the minimum diameter of the cell (47). This was determined by taking the average of several different fields at 40x.

Lactate Dehydrogenase (LDH) Assay. LDH assay was used as described by manufacturer (Promega CytoTox $\left.96{ }^{\circledR}\right)$. Cells were cultured in 96 well plates on the GBM papers for $24 \mathrm{~h}$ and $48 \mathrm{~h}$. LDH leakage was assessed in the supernatants of cells and compared to $100 \%$ lysed cells (using the lysis buffer). Fifty microliters of the cell supernatant was mixed with $50 \mu \mathrm{L}$ of LDH substrate mix in a new well-plate and incubated for 15 min at room temperature. Stop Solution ( $50 \mu \mathrm{L}$ per well) was added and absorbance was measured at $492 \mathrm{~nm}$ using a plate reader. The amount of LDH detected represented the number of dead cells. The percentage cytotoxicity was calculated using the following equation:

Percentage Cytotoxicity $=A_{492 n m}$ of treated cells $/ A_{492 \mathrm{~nm}}$ of totally lysed cells $\times 100$ 
Statistical Analysis. Data are represented as mean \pm standard deviation (SD). Cell microscopic experiments were carried out in at least two replicates, then analysing several fields of view per condition. LDH assay was carried out by an $n=4$. Statistical significance was tested using one-way ANOVA with Tukey's post-hoc test ( $p<$ $0.005^{* * *}, p<0.01 * *$ and $\left.p<0.05^{*}\right)$.

\section{Acknowledgments}

The authors thank staff members of the EM facility (Faculty of Life Sciences at the University of Manchester) for their assistance, and the Welcome Trust for equipment grant support to the EM facility. We are also grateful to Nigel Hodson from the Bio-AFM facility (Centre for Tissue Injury and Repair at the University of Manchester) for assistance and advice with the AFM instrumentation. We also would like to thank Patrick Hill from the University of Manchester and Geoff Parr from University of Salford for their assistance with the SEM. The Bio-imaging facility (Faculty of Life Sciences at the University of Manchester) microscopes used in this study were purchased with grants from the BBSRC, the Welcome Trust and the University of Manchester Strategic Fund. Special thanks go to Peter March/ Roger Meadows/ Steven Marsden for their help with the microscopy. X-ray photoelectron spectra were obtained at the National EPSRC XPS User's Service (NEXUS) at Newcastle University, an EPSRC Mid-Range Facility. This work was partially supported by the EU $7^{\text {th }}$ RTD Framework Programme, Graphene Flagship project (FP7-ICT-2013-FET-F-604391).

The authors declare no conicts of interest.

\section{References}

1. Geim AK (2009) Graphene: Status and Prospects. Science 324(5934):1530-1534.

2. Novoselov KS (2011) Nobel Lecture: Graphene: Materials in the Flatland*. Reviews of Modern Physics 83(3):837-849.

3. Wick P, et al. (2014) Classification Framework for Graphene-Based Materials. Angewandte Chemie International Edition 23(30):7714-7718.

4. Novoselov KS, et al. (2012) A roadmap for graphene. Nature 490(7419):192-200.

5. Jasim DA, Menard-Moyon C, Begin D, Bianco A, \& Kostarelos K (2015) Tissue distribution and urinary excretion of intravenously administered chemically functionalized graphene oxide sheets. Chemical Science 6(7):3952-3964.

6. Agarwal S, et al. (2010) Interfacing Live Cells with Nanocarbon Substrates. Langmuir 26(4):2244-2247.

7. Ryoo S-R, Kim Y-K, Kim M-H, \& Min D-H (2010) Behaviors of NIH-3T3 Fibroblasts on Graphene/Carbon Nanotubes: Proliferation, Focal Adhesion, and Gene Transfection Studies. ACS Nano 4(11):6587-6598.

8. Kalbacova M, Broz A, Kong J, \& Kalbac M (2010) Graphene substrates promote adherence of human osteoblasts and mesenchymal stromal cells. Carbon 48(15):4323-4329.

9. Li N, et al. (2011) The promotion of neurite sprouting and outgrowth of mouse hippocampal cells in culture by graphene substrates. Biomaterials 32(35):9374-9382.

10. Wang Y, et al. (2012) Fluorinated Graphene for Promoting Neuro-Induction of Stem Cells. Advanced Materials 24(31):4285-4290.

11. Ruiz ON, et al. (2011) Graphene Oxide: A Nonspecific Enhancer of Cellular Growth. ACS Nano 5(10):81008107.

12. Tu Q, et al. (2014) Effects of surface charges of graphene oxide on neuronal outgrowth and branching. Analyst 139(1):105-115.

13. Park SY, et al. (2011) Enhanced Differentiation of Human Neural Stem Cells into Neurons on Graphene. Advanced Materials 23(36). 
14. Li N, et al. (2013) Three-dimensional graphene foam as a biocompatible and conductive scaffold for neural stem cells. Scientific Reports 3:1604.

15. Girish CM, Sasidharan A, Gowd GS, Nair S, \& Koyakutty M (2013) Confocal Raman Imaging Study Showing Macrophage Mediated Biodegradation of Graphene In Vivo. Advanced Healthcare Materials 2(10):201200489.

16. O'Brien FJ (2011) Biomaterials \& scaffolds for tissue engineering. Materials Today 14(3):88-95.

17. Krishnamoorthy K, Umasuthan N, Mohan R, Lee J, \& Kim SJ (2012) Antibacterial Activity of Graphene Oxide Nanosheets. Science of Advanced Materials 4(11):1111-1117.

18. Lu B, et al. (2012) Graphene-based composite materials beneficial to wound healing. Nanoscale 4(9):29782982.

19. Pryzhkova MV (2013) Concise review: carbon nanotechnology: perspectives in stem cell research. Stem Cells Transl Med 2(5):376-383.

20. Ali-Boucetta $\mathrm{H}$, et al. (2013) Purified graphene oxide dispersions lack in vitro cytotoxicity and in vivo pathogenicity. Advanced Healthcare Materials 2(3):433-441.

21. Barbolina I, et al. (2016) Purity of graphene oxide determines its antibacterial activity. 2D Materials 3(2):025025.

22. Kostarelos K \& Novoselov KS (2014) Exploring the Interface of Graphene and Biology. Science 344(6181):261-263.

23. Bussy C, J asim DA, Lozano N, Terry D, \& Kostarelos K (2015) The Current Graphene Safety Landscape - a Literature Mining Exercise. Nanoscale.

24. Li W, Wang J, Ren J \& Qu X (2013) 3D graphene oxide-polymer hydrogel: near-infrared light-triggered active scaffold for reversible cell capture and on-demand release. Advanced Materials 25(46):6737-6743.

25. Boehm HP, Clauss A, \& Hoffmann U (1960) Graphite oxide and its membrane properties. J ournal de Chimie Physique 58(12):110-117.

26. Dikin DA, et al. (2007) Preparation and characterization of graphene oxide paper. Nature 448(7152):457-460.

27. Nair RR, Wu HA, J ayaram PN, Grigorieva IV, \& Geim AK (2012) Unimpeded Permeation of Water Through Helium-Leak-Tight Graphene-Based Membranes. Science 335(6067):442-444.

28. J oshi RK, et al. (2014) Precise and Ultrafast Molecular Sieving Through Graphene Oxide Membranes. Science 343(6172):752-754.

29. Su Y, et al. (2014) Impermeable barrier films and protective coatings based on reduced graphene oxide. Nature Communications 5:4843.

30. Wallace GG, Higgins MJ , Moulton SE, \& Wang C (2012) Nanobionics: the impact of nanotechnology on implantable medical bionic devices. Nanoscale 4(15):4327-4347.

31. J asim DA, Lozano N, \& Kostarelos K (2016) Synthesis of few-layered, high-purity graphene oxide sheets from different graphite sources for biology. 2D Materials 3(1):014006.

32. J asim DA, et al. (2016) Thickness of functionalized graphene oxide sheets plays critical role in tissue accumulation and urinary excretion: A pilot PET/CT study. Applied Materials Today 4:24-30.

33. Orecchioni M, et al. (2016) Molecular and Genomic Impact of Large and Small Lateral Dimension Graphene Oxide Sheets on Human Immune Cells from Healthy Donors. Adv Healthc Mater 5(2):276-287.

34. Ferrari AC (2007) Raman spectroscopy of graphene and graphite: Disorder, electron-phonon coupling, doping and nonadiabatic effects. Solid State Communications 143(1-2):47-57.

35. Choi E-Y, et al. (2010) Noncovalent functionalization of graphene with end-functional polymers. J ournal of Materials Chemistry 20(10):1907-1912.

36. Rattana, et al. (2012) Preparation and characterization of graphene oxide nanosheets. Procedia Engineering $32(0): 759-764$

37. Sun $X$, et al. (2008) Nano-graphene oxide for cellular imaging and drug delivery. Nano Res. 1(3):203-212.

38. Wang G, et al. (2009) Synthesis of enhanced hydrophilic and hydrophobic graphene oxide nanosheets by a solvothermal method. Carbon 47(1):68-72.

39. Willard HH, Merritt J , L. L., A. DJ , \& Settle J , F. A. (1988) Instrumental methods of analysis (Wadsworth, Inc, California) 7th Ed.

40. Williams DH \& Feleming I (1995) Spectroscopic methods in organic chemistry (McGraw-Hill International (UK) limited, England) 5th Ed.

41. Pretsch E, Clerc T, Seibl J \& Simon W (1989) Tables of Spectral Data for Structure Determination of Organic Compounds (Springer-Verlag, Brooklyn, NY, U.S.A).

42. Namvari M \& Namazi H (2014) Sweet graphene I: toward hydrophilic graphene nanosheets via click grafting alkyne-saccharides onto azide-functionalized graphene oxide. Carbohydr Res 396:1-8.

43. Neelgund GM, Oki A, \& Luo Z (2014) ZnO and cobalt phthalocyanine hybridized graphene: efficient photocatalysts for degradation of rhodamine B. J Colloid Interface Sci 430:257-264.

44. Shang J, et al. (2012) The origin of fluorescence from graphene oxide. Scientific Reports 2:792.

45. Liu Z, Duan X, Qian G, Zhou X, \& Yuan W (2013) Eco-friendly one-pot synthesis of highly dispersible functionalized graphene nanosheets with free amino groups. Nanotechnology 24(4):0957-4484.

46. Verebes GS, et al. (2013) Hyperspectral enhanced dark field microscopy for imaging blood cells. J Biophotonics 6(11-12):960-967.

47. J asim DA, et al. (2016) The Effects of Extensive Glomerular Filtration of Thin Graphene Oxide Sheets on Kidney Physiology. ACS Nano 10(12):10753-10767. 


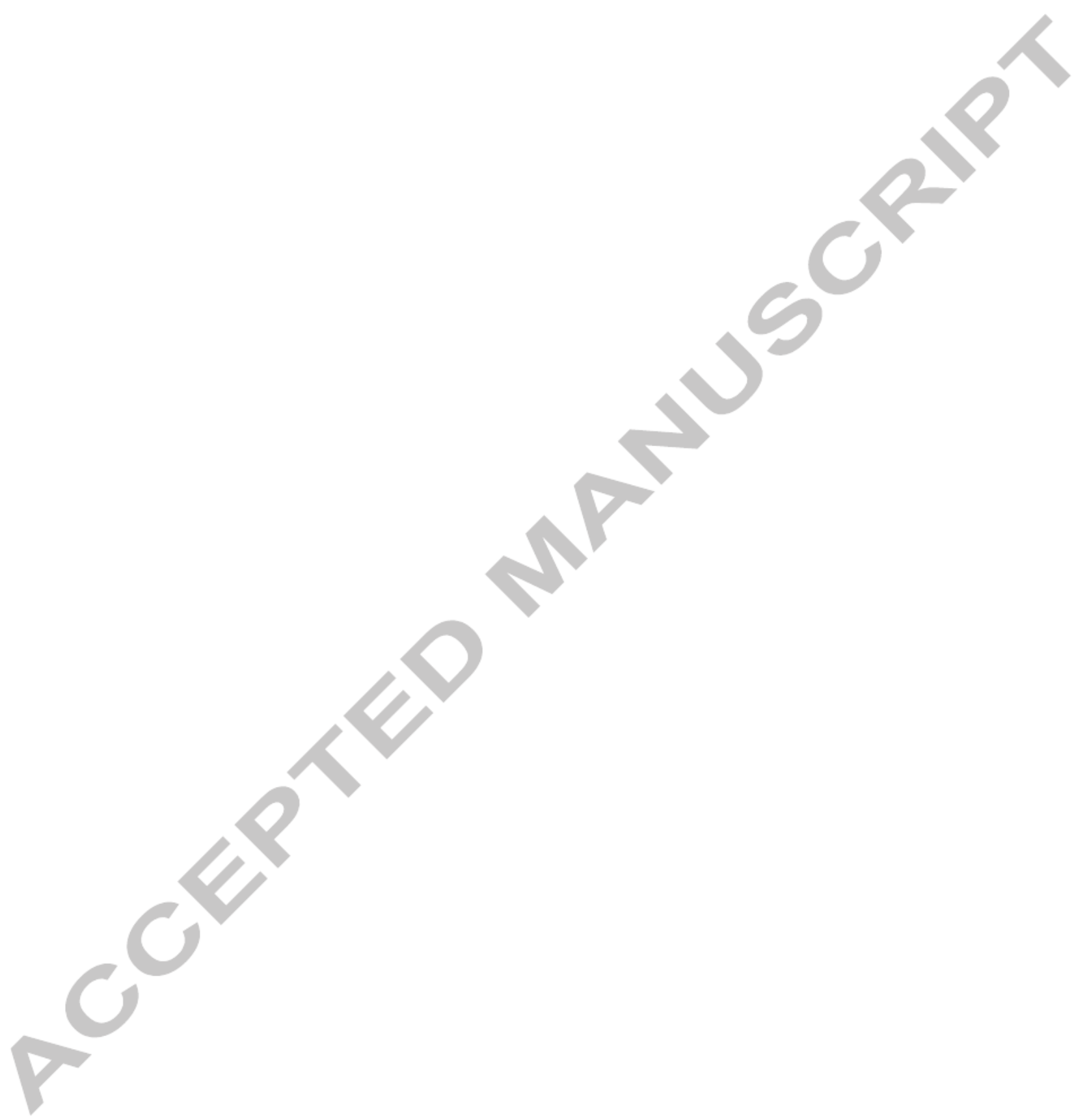




\section{FIGURE LEGENDS}

Figure 1. Structural characterisation of GTO, I-GO and s-GO in aqueous solution. (A) TEM images and (B) AFM height images (C) AFM lateral size particle analysis for the I-GO and s-GO (D) AFM thickness analysis for the I-GO and s-GO.

Figure 2. Morphology and structural characterisation of GTO, I-GO and s-GO papers. (A) Photographs of the papers; (B) Bright field images of the papers (without cells) at two different magnifications; (C) SEM surface analysis, (i) topographic and (ii) cross section imaging; (D) Corresponding schematic representations for the predicted arrangement of graphene oxide sheets in the papers.

Figure 3. Physicochemical characterisation of GTO, I-GO and s-GO papers. (A) Raman spectroscopy, (B) FTIR, (C) TGA, (D) XPS survey spectra and (E) XPS C1s high resolution spectra for the papers. GTO and GO-B (dark grey).

Figure 4. Cell growth and cytotoxicity of A549 cells on GTO, I-GO and s-GO papers. (A) Bright field of A549 cells grown on plastic cover slips (control) and with the GTO and the two GO papers. (B) Surface covered by cells on the different papers compared to control counted by Image J software, using 3 different regions of interest, with two replicates (fields at 10x magnification). (C) Cytotoxicity was determined using LDH assay. All data are mean $\pm S D(n=4)$ and statistical significance was tested using one way ANOVA with Tukey's post-hoc test, $p<0.005^{* * *}$ against positive control (lysed

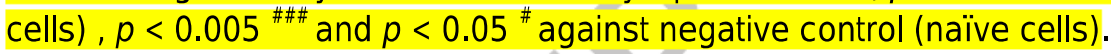



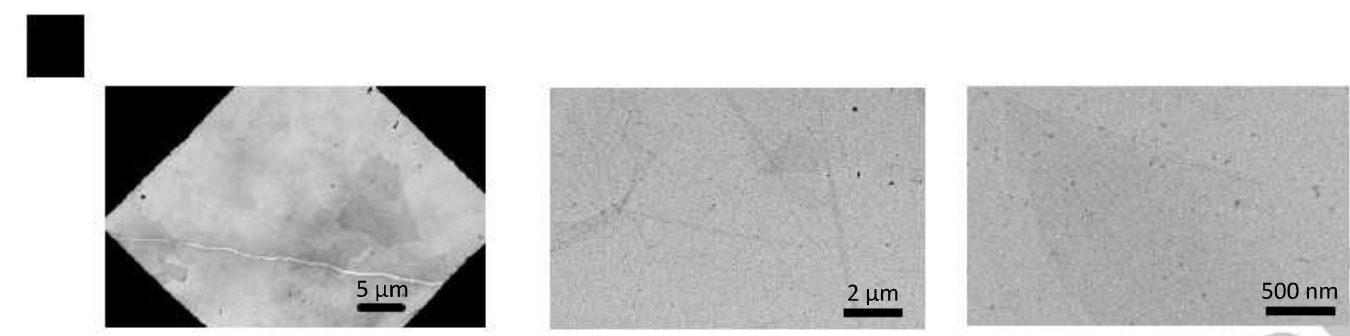

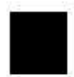
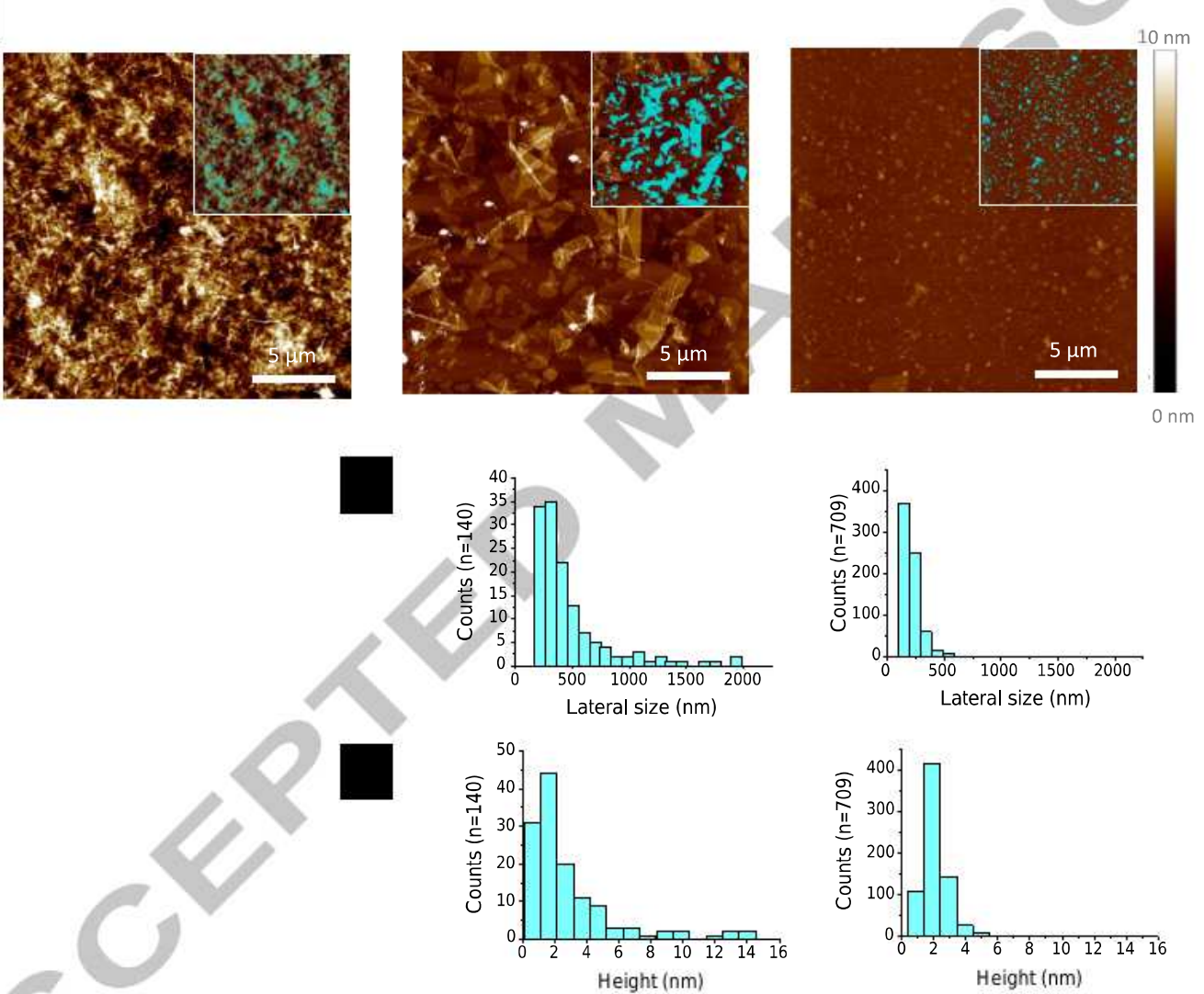

Figure 1. Structural characterisation of GTO, I-GO and s-GO in aqueous solution. (A) TEM images and (B) AFM height images (C) AFM lateral size particle analysis for the I-GO and s-GO (D) AFM thickness analysis for the I-GO and s-GO. 


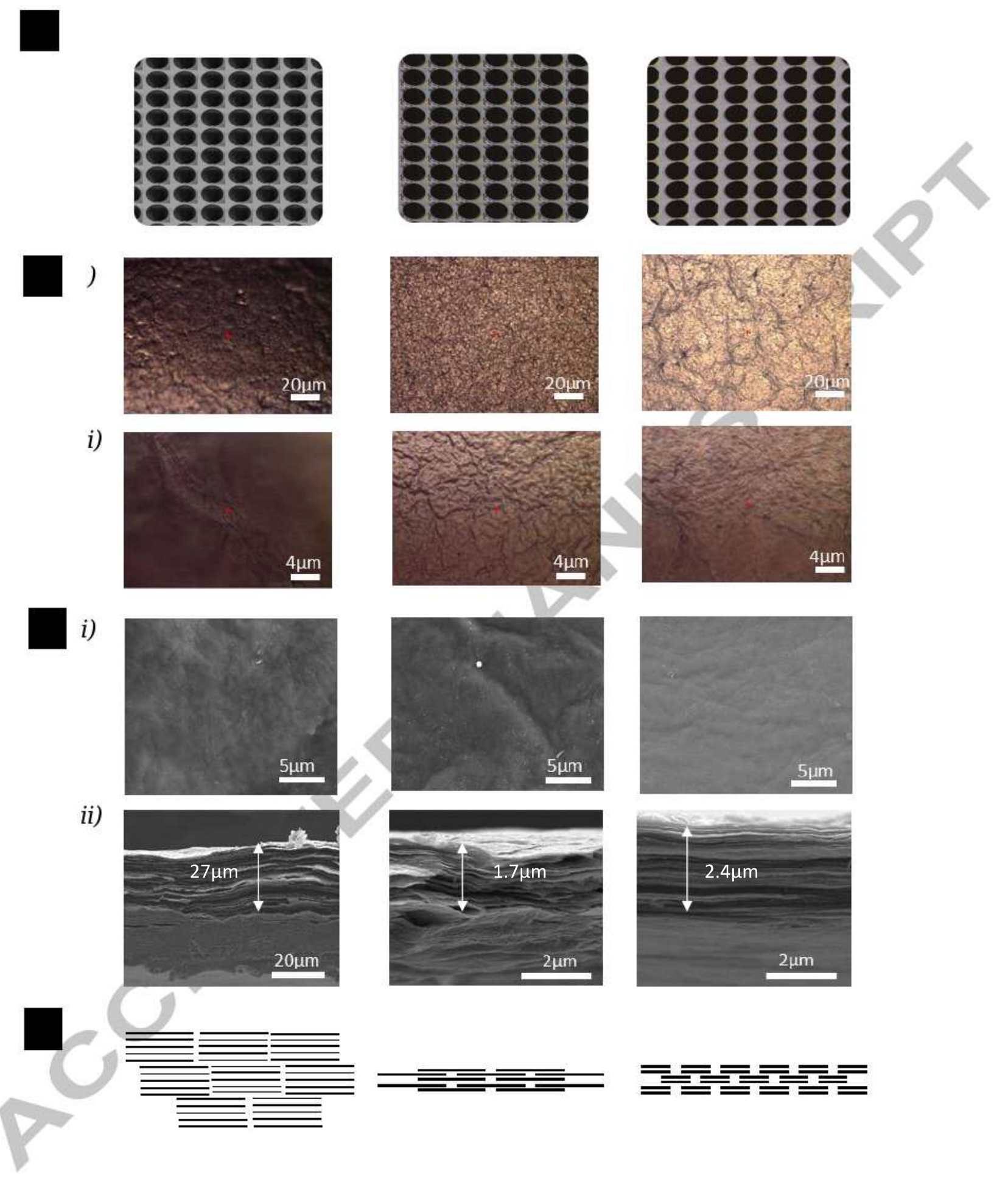

Figure 2. Morphology and structural characterisation of GTO, I-GO and S-GO papers. (A) Photographs of the papers; (B) Bright field images of the papers (without cells) at two different magnifications; (C) SEM surface analysis, (i) topographic and (ii) cross section imaging; (D) Corresponding schematic representations for the predicted arrangement of graphene oxide sheets in the papers. 

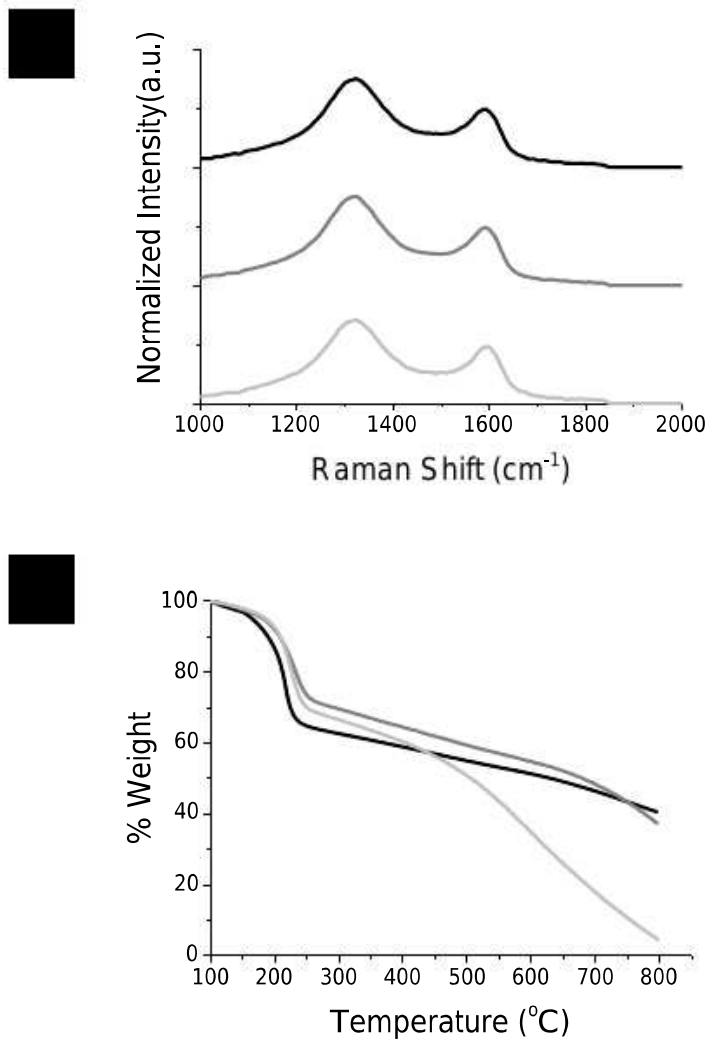

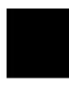
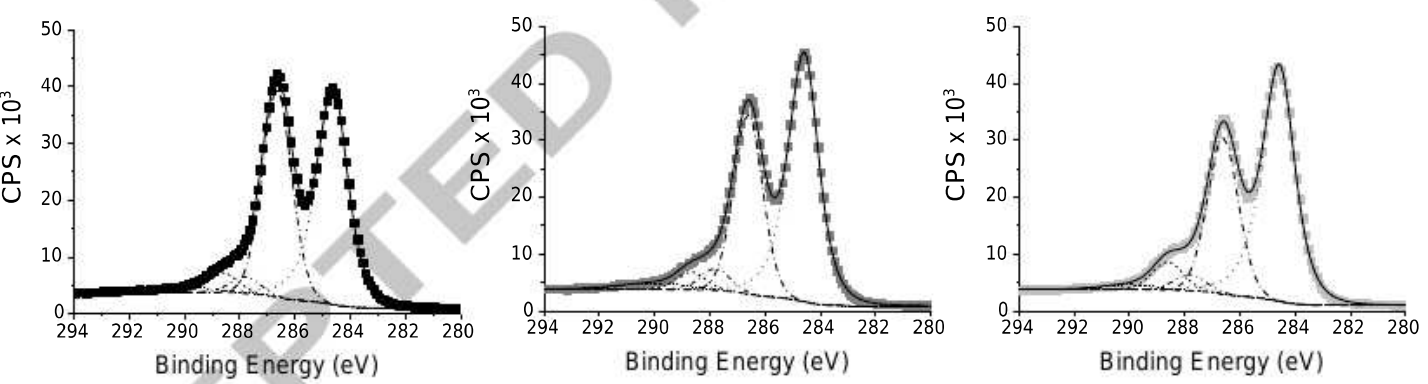

Figure 3. Physicochemical characterisation of GTO, I-GO and S-GO papers. (A) Raman spectroscopy, (B) FTIR, (C) TGA, (D) XPS survey spectra and (E) XPS C1s high resolution spectra for the papers. GTO and GO-B (dark grey). 

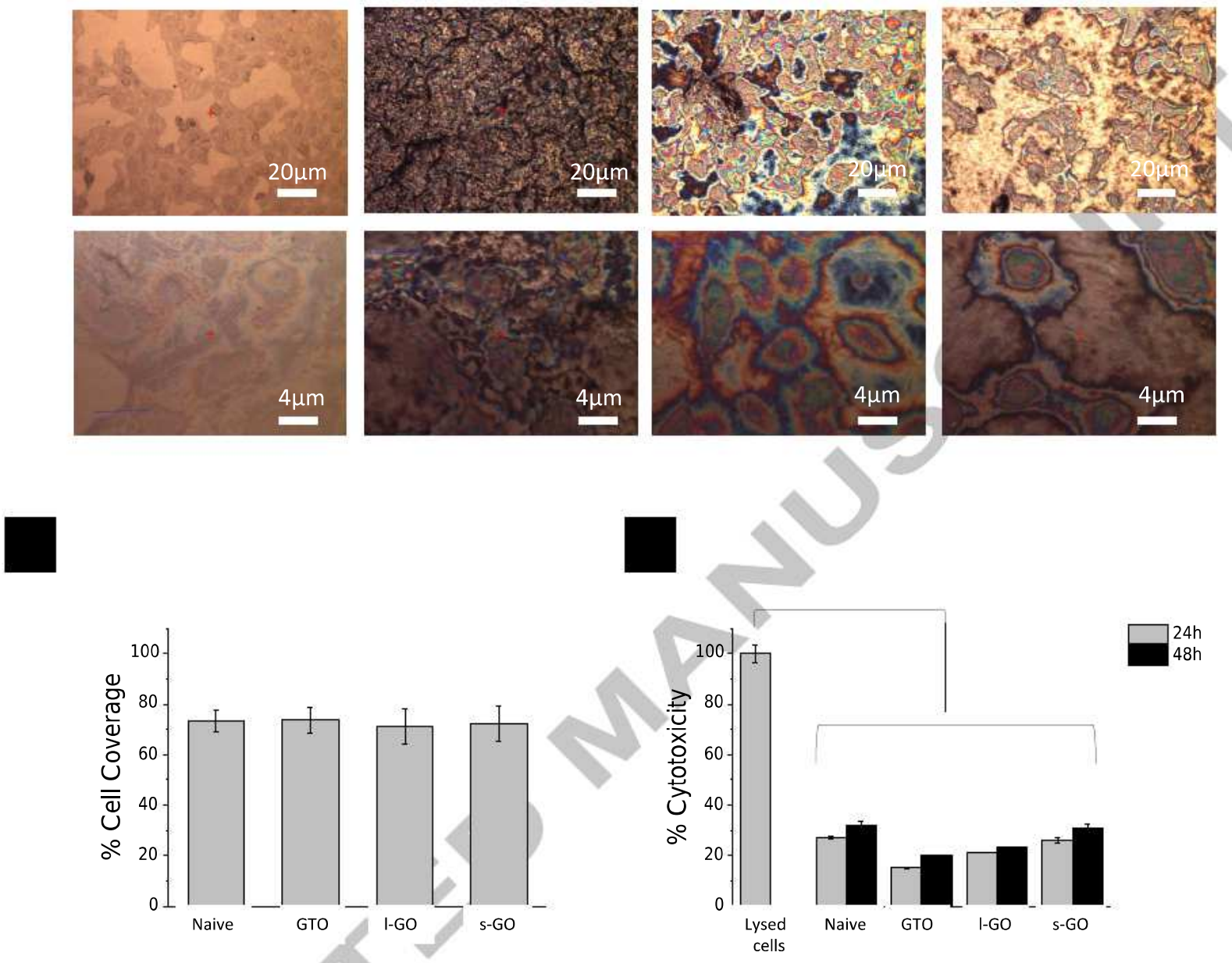

Figure 4. Cell growth and cytotoxicity of A549 cells on GTO, I-GO and s-GO papers. (A) Bright field of A549 cells grown on plastic cover slips (control) and with the GTO and the two GO papers. (B) Surface covered by cells on the different papers compared to control counted by Image J software, using 3 different regions of interest, with two replicates (fields at 10x magnification). (C) Cytotoxicity was determined using LDH assay. All data are mean $\pm S D(n=4)$ and statistical significance was tested using one way ANOVA with Tukey's post-hoc test, $p<0.005 * * *$ against positive control (lysed

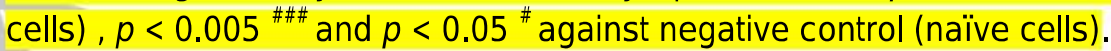




\section{Supporting Information}

Supporting Tables (Table S1 and S2)

Table S1. Surface chemical composition from the XPS survey spectra of the GBM papers, namely GTO, I-GO and S-GO. Purity as considering $\mathrm{O} 1 \mathrm{~s}$ and $\mathrm{Cls}$ content while other elemental composition is considered as chemical contamination. 
Table S2. Quantification of the surface-available functional groups from the XPS C1s high resolution spectra for the GBM papers, namely GTO, I-GO and s-GO, after deconvolution into 5 components: pi$\mathrm{pi}^{*}$ transition $\left(\pi-\Pi^{*}\right)$, carboxylic $(\mathrm{O}-\mathrm{C}=\mathrm{O})$, carbonyl $(\mathrm{C}=\mathrm{O})$, epoxide $(\mathrm{C}-\mathrm{O}-\mathrm{C})$, hydroxyl $(\mathrm{C}-\mathrm{OH})$ and $\mathrm{C}$ $s p^{3}$ and $s p^{2}(\mathrm{C}-\mathrm{C} \& \mathrm{C}=\mathrm{C})$. 


\section{Supporting Figures (Figures S1-S8)}
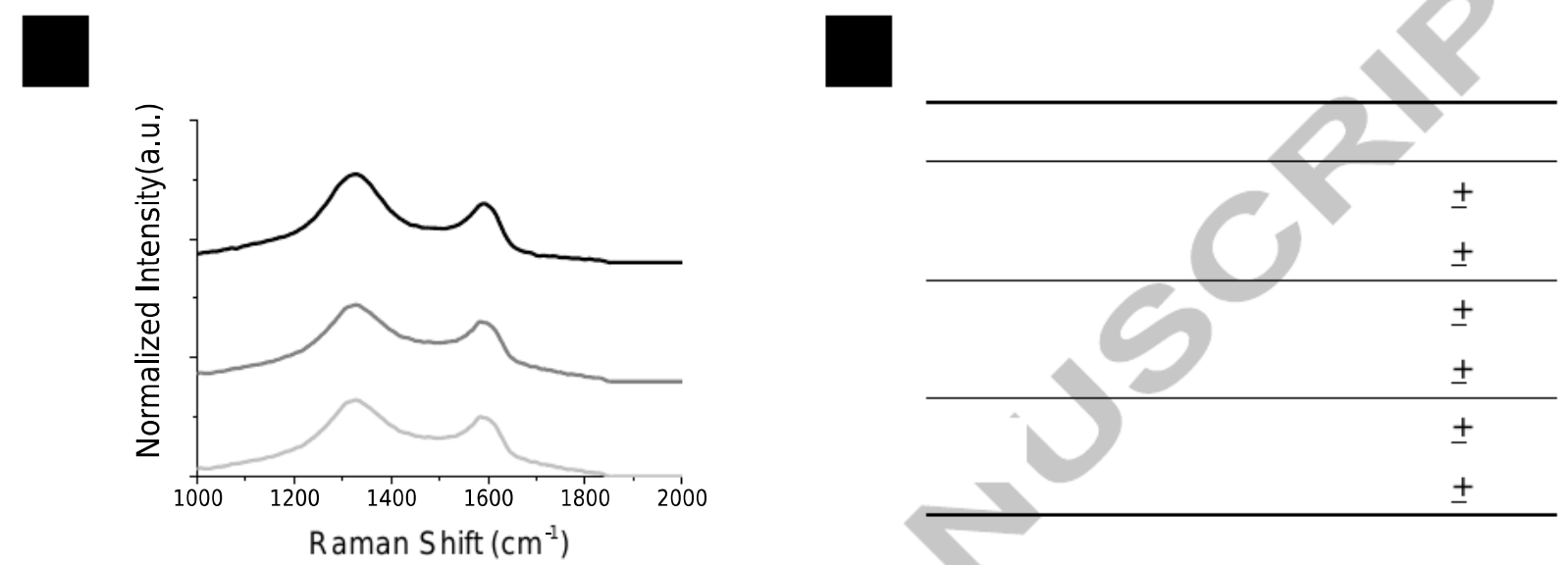

Figure S1. Raman spectroscopy analysis of the GMB in aqueous solution. (A) Raman spectra of GTO, I$\mathrm{GO}$ and s-GO used for the preparation of the GBM papers and (B) the tabulated values comparing the $\mathrm{I}_{\mathrm{D}} / \mathrm{I}_{\mathrm{G}}$ ratio for the GBM in aqueous solution versus in paper form. 

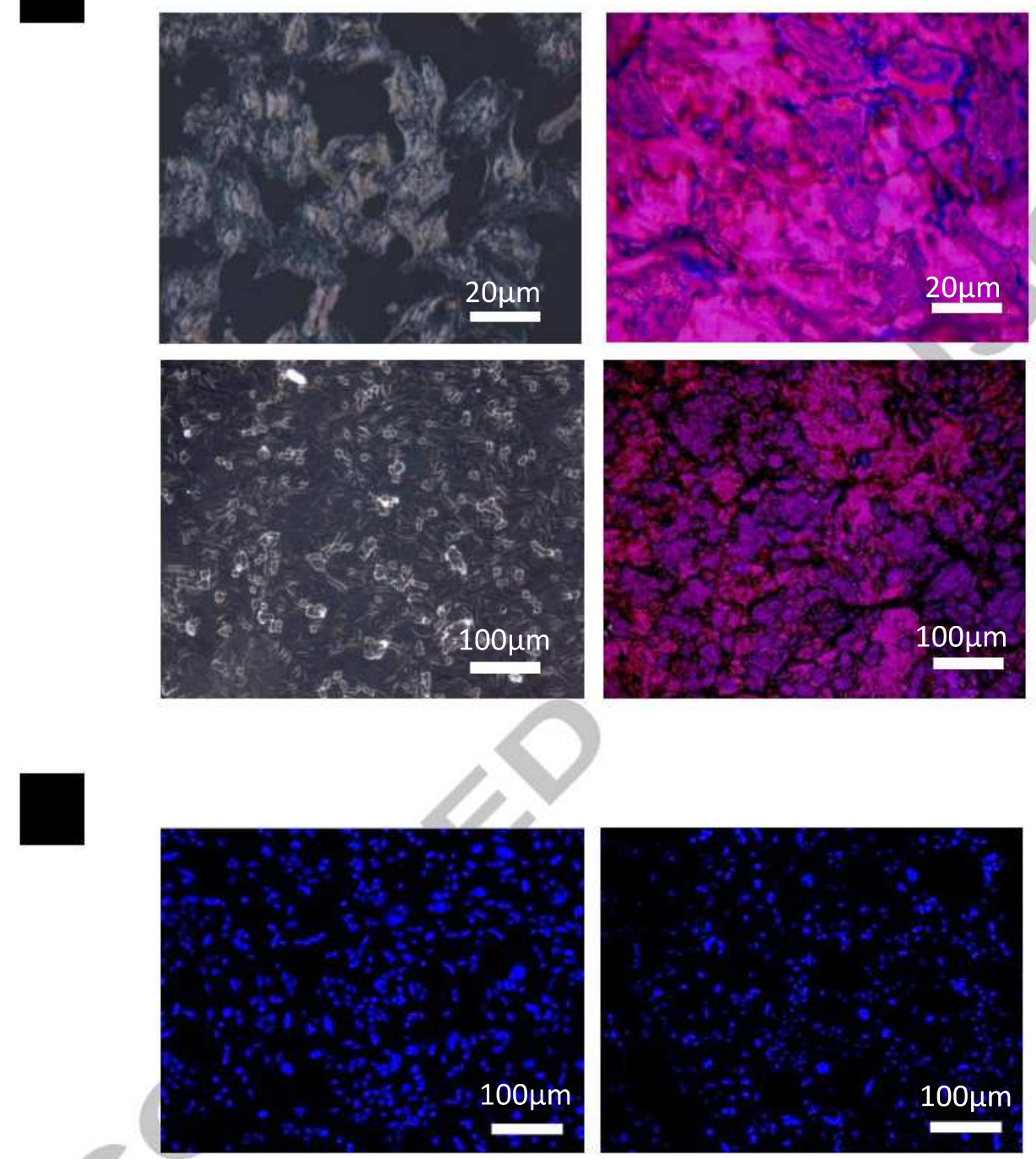

Figure S2. Cell growth of A549 and SH-SY5Y cells on GTO paper. (A) Enhanced dark field microscopic images of A549 cells (top) and SH-SY5Y cells (bottom) grown on glass cover slips (control, right) and GTO paper (left). Right panels represent enhanced contrast image created by the Zen software for both cell lines. (B) Fluorescence microscopy of A549 cells stained with DAPI molecular stain grown on glass cover slips (control) and on the GTO paper. 


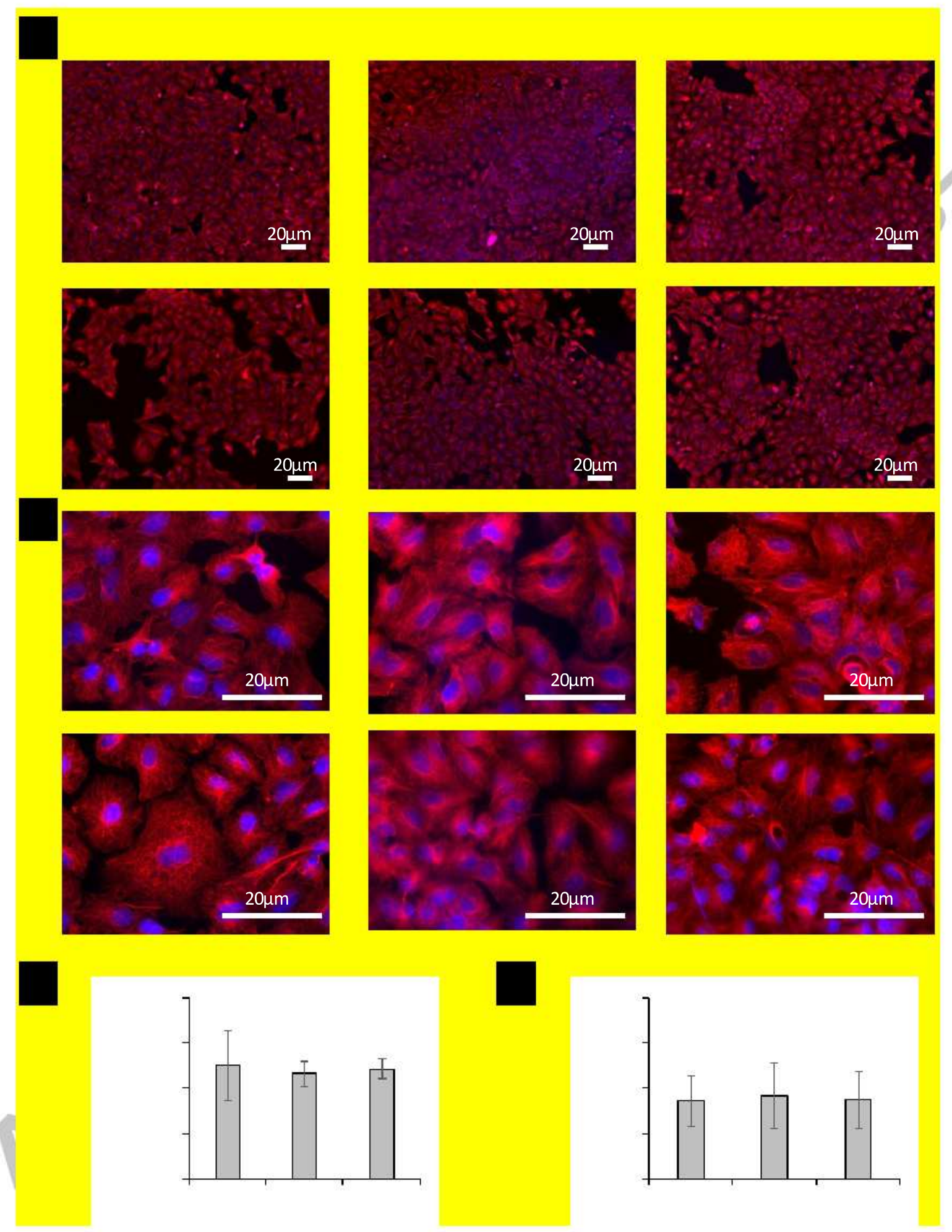

Figure S3. Cell growth of A549s on GTO and I-GO papers. (A) Florescence microscopic images of cells stained with $\alpha$-tubulin and DAPI on control, GTO and I-GO paper (at 10x). (B) Florescence microscopic images of cells stained with a-tubulin and DAPI on control, GTO and I-GO paper (at 40x). (C) Cell number counts graph. (D) Cell aspect ratio graph. All data are mean \pm SD and statistical significance was tested using one-way ANOVA with Tukey's post-hoc test, experiments were performed in duplicates and several fields of view were examined. 

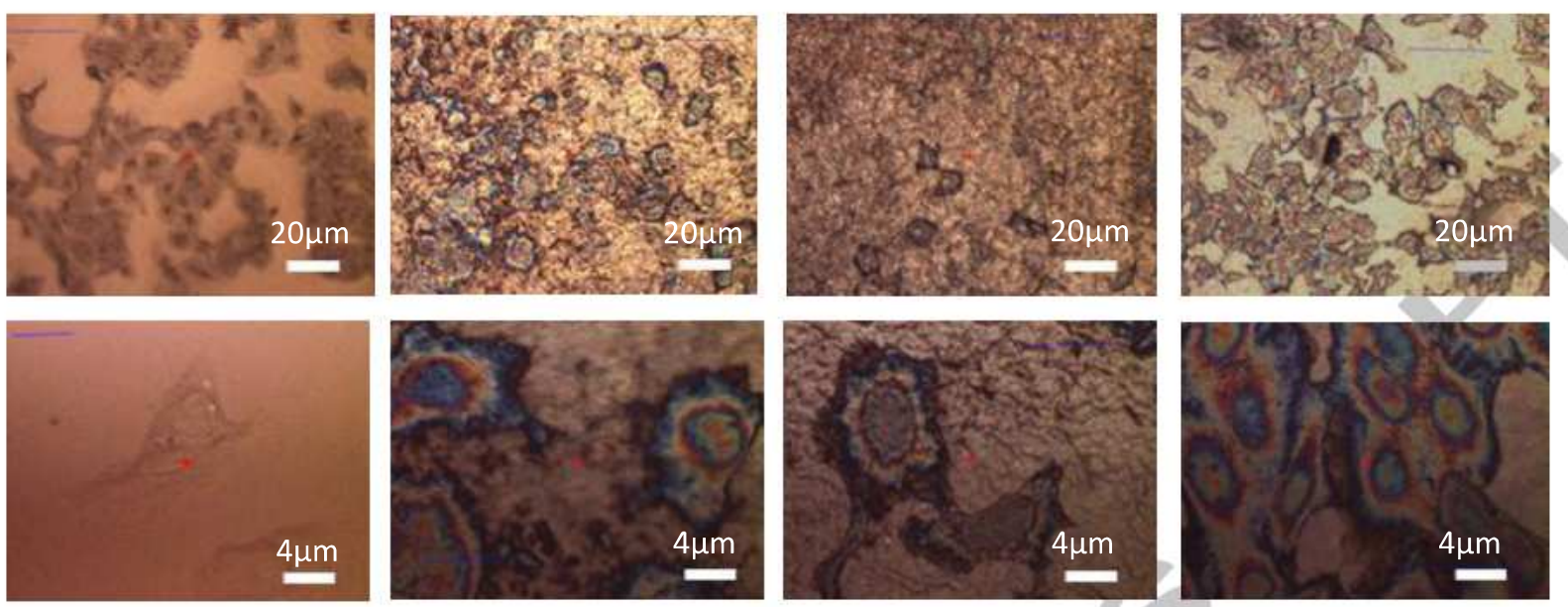

Figure S4. Optical microscopy (bright field) of A549 cells grown on glass cover slips (control) and on GBM papers; GTO, I-GO and s-GO. Cells were visualized using an upright optical microscope. 


\section{.}
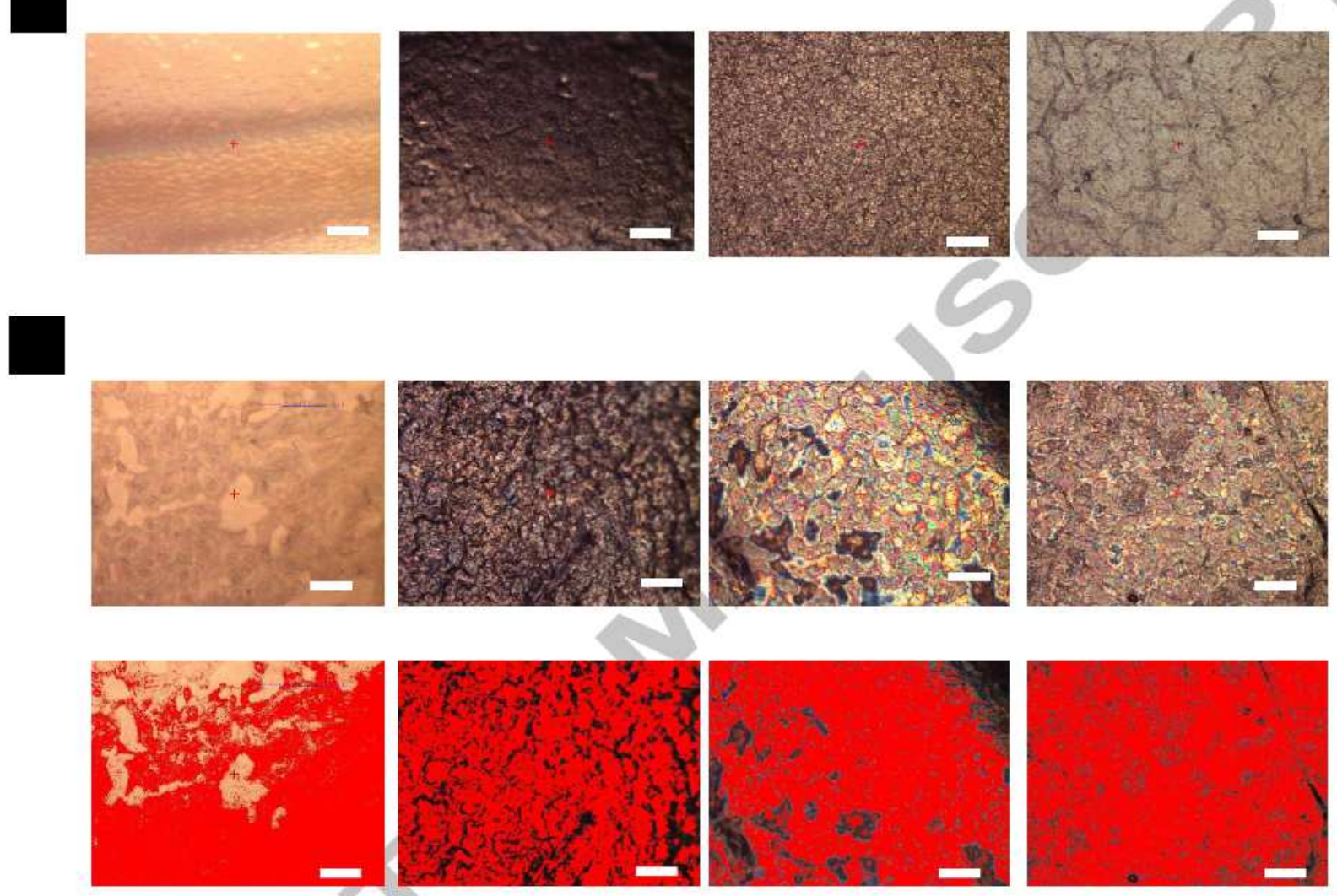

Figure S5. Human lung epithelial (A549) cell growth, spreading and confluency. (A) Bright field images of the control (plastic cover slips) and GBM papers alone (without cells) and (B) A549 cells grown on plastic cover slips (control) and on GBM papers, bottom images represent Imagej selected areas for quantification (highlighted mask in red). GTO, I-GO and s-GO. All scale bars are $20 \mu \mathrm{m}$. Cells were visualized using an upright optical microscope. 
Three dierent oxidised graphene papers have been produced from starng materials diering in thickness and lateral dimensions.

2] The resulting papers had diering topography and structural arrangements, while having similar physicochemical characteriscs.

] Two mammalian cell lines with dissimilar morphological properties were cultured on the papers.

[? All three papers were biocompatible and supported the growth of the cells with no cytotoxicity determined. 